\title{
REKONSEPTUALISASI KONSTRUK KUALITAS LAYANAN SPESIFIK PADA KONTEKS PERGURUAN TINGGI
}

\author{
Fachri Eka Saputra* \\ Manajemen, Ekonomi dan Bisnis, Universitas Bengkulu, Indonesia
}

\begin{abstract}
Abstrak
Studi ini bertujuan untuk menguji kembali skala pengukuran kualitas layanan yang mengacu pada multi dimensional konsep. Jenis penelitian ini adalah penelitian deskriptif kuantitatif. Penarikan sampel dalam penelitian ini dilakukan secara acak (probability sampling) dengan teknik sampling acak berlapis (stratified random sampling) dalam memperoleh informasi dari responden. Jumlah sampel yang digunakan adalah 200 orang. Hasil penelitian menunjukkan bahwa kualitas layanan dapat diklasifikasikan ke dalam 6 Faktor. Faktor tersebut terdiri dari Faktor 1 yang berfokus layanan administratif; Faktor 2 yang berfokus pada sarana dan prasarana; Faktor 3 yang berfokus pada kualitas pengajaran; Faktor 4 yang berfokus pada pengalokasian sumber daya; Faktor 5 yang berfokus pada kemudahan peminjaman ruang; dan Faktor 6 berfokus pada responsif dosen terhadap keluhan mahasiswa. Institusi pendidikan tinggi dan setiap unit yang dibawahinya diharapkan memerhatikan faktor-faktor ini dalam menyusun kebijakan dan program pengembangan.
\end{abstract}

Kata Kunci: Kualitas Layanan, HEdPerf (Higher Education Performance), HiEdQual (Higher Education Quality), Perguruan Tinggi.

\begin{abstract}
This study aims to reexamine the scale of service quality measurement that refers to multi-dimensional concepts. This type of research is quantitative descriptive research. This research is a quantitative research. Sampling in this study was carried out randomly by using probability sampling with a stratified random sampling technique in obtaining information from respondents. The number of samples used was 200 people in each department in the Economic and Business Faculty, University of Bengkulu. The results showed that service quality can be classified into 6 factors. These factors consist of Factor 1 which focuses on administrative services; Factor 2 which focuses on facilities and infrastructure; Factor 3 which focuses on the quality of teaching; Factor 4, which focuses on resource allocation; Factor 5, which focuses on the ease of borrowing space; and Factor 6 focuses on lecturer responsiveness to student complaints. The higher education institution and each unit under it are expected to pay attention to these factors in developing policies and programs.
\end{abstract}

Keyword: Service Quality, HEdPerf (Higher Education Performance), HiEdQual (Higher Education Quality), Higher Education Institution.

Article History: Received: (12-03-2020); Revised: (18-04-2020); and Published: (30-04-2020) Copyright @ 2020 Saputra, F.E.

How to cite this article: Saputra, F. E. (2020). Rekonseptualisasi Konstruk Kualitas Layanan Spesifik pada Konteks Perguruan Tinggi. Managament Insight: Jurnal IImiah Manajemen 15 (1), 49-64. 


\section{PENDAHULUAN}

Peningkatkan mutu penyelenggaraan kegiatan pendidikan dan pengajaran sangat berkaitan erat dengan mahasiswa sebagai objek (pelaku) di dalamnya. Mahasiswa berperan sebagai ujung tombak penting tolak ukur penyelenggaraan kegiatan pendidikan dan pengajaran. Mahasiswa merupakan konsumen sebenarnya dari pemasaran produk perguruan tinggi. Program studi yang dinaungi oleh tiap-tiap fakultas yang ada di masing-masing perguruan tinggi berupaya untuk menarik kandidat terbaik calon mahasiswa lulusan sekolah menengah atas (SMA) di tingkat lokal, nasional, maupun internasional.

Upaya dalam mengantisipasi persaingan memperebutkan input calon mahasiswa terbaik dapat dilakukan dengan secara kontinu meningkatkan kualitas layanan bagi mahasiswa. Kualitas layanan bagi institusi pendidikan merupakan aspek fundamental untuk keunggulan pendidikan (Dyson, et al., 1996). Ketika mahasiswa merasakan institusi pendidikan menyediakan lingkungan belajar yang memfasilitasi, infrastruktur yang memadai dan mereka mampu mengembangkan bakat di dalam organisasi, maka mahasiswa akan termotivasi untuk lebih baik belajar di bidang akademik (Alridge dan Rowley, 2001). Kualitas layanan pendidikan juga harus memperhatikan sistem keamanan, interior dan eksterior ruangan, ketersediaan fasilitas multimedia, perpustakaan, dan fasilitas lainnya yang dikelola dan diperbaharui dengan baik (Dick dan Basu, 1994).

Sejumlah studi telah menyelidiki pentingnya kualitas layanan dan instrumen pengukurannya bagi institusi perguruan tinggi (O'Neill dan Palmer, 2004; Parri, 2006; Quinn et al., 2009; Annamdevula dan Bellamkonda, 2016). Meskipun kualitas layanan sudah banyak diteliti di dunia bisnis, namun tetap menjadi isu dan topik yang relevan untuk dipelajari pada konteks perguruan tinggi (Annamdevula dan Bellamkonda, 2016). Hal ini disebabkan karena tidak ditemukannya konsesus pada berbagai penelitian empiris tentang dimensi dan anteseden yang disepakati secara umum mengenai kualitas layanan di perguruan tinggi dari perspektif mahasiswa (Sultan dan Wong, 2012). Kualitas layanan di sektor pendidikan tinggi merupakan konsep multi aspek dan kompleks, sehingga tidak ada satupun definisi yang reliabel mengenai kualitas (Harvey dan Green, 1993). Konsekuensinya, konsesus mengenai "cara terbaik untuk mendefinisikan dan mengukur kualitas layanan" pada konteks perguruan tinggi masih belum ditemukan hingga saat ini (Clewes, 2003). Namun demikian, para peneliti mengetahui pentingnya mengukur kualitas layanan di perguruan tinggi dan mereka telah berupaya untuk mendefinisikannya dengan cara mereka masing-masing (Annamdevula dan Bellamkonda, 2016).

Studi ini bertujuan untuk menguji kembali skala pengukuran kualitas layanan yang mengacu pada multi dimensional konsep yang diusulkan oleh Annamdevula dan Bellamkonda (2016). Perbaikan kualitas layanan secara berkala yang ditinjau dari perspektif pengguna layanan merupakan dasar bagi kesuksesan pengembangan bisnis dalam lingkungan yang kompetitif, dinamis, dan kompleks (Bolton et al., 2004; Kotler, 
2000). Upaya untuk mengukur kualitas layanan secara berkala sangat berguna untuk mengembangkan program yang sesuai guna mempromosikan, membangun, mengembangkan, dan mempertahankan kesuksesan hubungan jangka panjang dengan mahasiswa maupun mantan mahasiswa (Annamdevula dan Bellamkonda, 2016).

\section{TINJAUAN PUSTAKA}

\section{Kualitas Layanan}

Dasar teori kualitas jasa terletak pada kualitas produk dan literatur kepuasan konsumen (Brady dan Cronin, 2001; Parasuraman et al., 1985, 1988). Konseptualisasi awal dari kualitas jasa didasarkan pada paradigma diskonfirmasi yang digunakan dalam literatur barang fisik (Cordozo, 1965; Churchill dan Surprenant, 1982; Howard dan Sheth, 1969; Oliver, 1977, 1980; Olshavsky dan Miller; Olson dan Dover, 1976 dalam Brady dan Cronin, 2001). Paradigma diskonfirmasi juga didasarkan pada model Parasuraman et al., $(1985,1988)$ dalam model SERVQUAL, yang memandang kualitas jasa sebagai gap (kesenjangan) antara tingkat jasa yang diharapkan dan persepsi konsumen dari kinerja layanan aktual yang mereka terima.

SERVQUAL merupakan sebuah model empiris yang dipergunakan untuk mengevaluasi kualitas layanan. Instrumen SERVQUAL bergungsi untuk menilai persepsi dan harapan konsumen mengenai kualitas layanan. Kualitas pelayanan yang baik adalah yang dapat melebihi harapan pelanggan. Harapan pelanggan merupakan keyakinan mengenai layanan yang berfungsi sebagai standar penilaian kinerja layanan (Zeithaml dan Bitner, 2000). Harapan pelanggan merupakan persepsi pelanggan terkait layanan haruslah melebihi layanan yang diberikan oleh organisasi (Parasuraman et al, 1988). Persepsi pelanggan dapat diketahui dengan membandingkan harapan pelanggan sebelum adanya layanan dengan aktualisasi layanan yang dirasakan oleh pelanggan. Layanan akan diangggap baik jika persepsi melebihi harapan, layanan akan dianggap memadai jika sama dengan harapan dan layanan dianggap buruk jiika persepsi tidak sesuai dengan harapan (Vazquez, 2001).

SERVQUAL merupakan model paling populer yang dipergunakan untuk mengukur kualitas layanan. SERVQUAL dikembangkan oleh Parasuraman $(1985,1988)$. SERVQUAL dirancang untuk menjadi instrumen yang dapat diterapkan secara luas dari berbagai macam layanan. Model SERVQUAL dapat mengukur kesenjangan kualitas layanan dalam sebuah organisasi, sehingga dapat menjadi alat untuk mendiaknosa dan mengidentifikasi kekurangan kualitas layanan dalam suatu organisasi (Parasuraman et al., 1988). Pada awalnya SERVQUAL terdiri dari 10 dimensi untuk mengukur kualitas pelayanan yang terdiri dari: reliability, responsiveness, competence, access, courtesy, communication, credibility, security, understanding/knowing, dan tangible.

Namun, Parasuraman et al. (1988) dapat menemukan intisari dari dimensi kualitas layanan, dimensi kualitas layanan yang semula terdiri dari sepuluh dimensi dilebur menjadi lima dimensi. Dimensi competence, courtesy, credibility dan security digabung menjadi bagian dari dimensi assurance. Dimensi access, communication dan 
understanding/knowing digabung menjadi bagian dari dimensi emphaty. Sehingga, dimensi kualitas layanan berdasarkan model SERVQUAL terdiri dari: reliability, responsiveness, assurance, empathy, dan tangibles.

Dimensi tangibles, assurance dan emphaty memiliki hubungan yang sangat signifikan terhadap kepuasan pelanggan (Ahmed et al., 2010). Sementara Lau et al., (2013) mengungkapkan bahwa reliability, responsiveness, assurance, emphaty dan tangibles memiliki pengaruh yang positif pada kepuasan pelanggan. Bagi dunia penididikan, kualitas layanan merupakan aspek penting untuk keunggulan bersaing sebuah perguruan tinggi (Dyson et al., 1996). Ketika mahasiswa merasakan lembaga pendidikan memberikan lingkungan belajar yang difasilitasi, infrastruktur yang memadai dan mereka mampu mengembangkan bakat di dalam organisasi, maka mahasiswa akan termotivasi untuk lebih baik belajar di bidang akademik (Alridge dan Rowley, 2001). Selain termotivasi, mahasiswa juga akan merasakan kepuasan terhadap kualitas pendidikan (Zeithaml, 1988). Selain fasilitas dan infrastuktur yang memadai, kemampuan intelektual guru atau dosen, pengembangan professional, transparansi dalam evaluasi mahasiswa dan umpan balik dalam pelatihan merupakan fitur penting dalam mengembangkan mental mahasiswa (Spooreen et al., 2007).

Lebih lanjut, selain aplikasi SERVQUAL, terdapat beberapa konsep-tualisasi lainnya yang diperoleh peneliti hasil dari review literatur beberapa jurnal ilmiah dari penelitian sebelumnya. Salah satu dari konseptualisasi ini akan dipergunakan sebagai instrumen pengukuran spesifik pada konteks perguruan tinggi.

\section{HEdPERF (Higher Education PERformance)}

Sebagaimana telah dijelaskan sebelumnya, berbagai penelitian terdahulu telah banyak yang mengidentifikasi konsep kualitas layanan pada berbagai perusahaan jasa. Penyelidikan penelitian mengenai kualitas layanan sudah dilakukan sejak Tahun 1980an. Konsep kualitas pertama kali diperkenalkan oleh Juran (1974) serta Edwards (1982). Gronroos (1984) mempersempit konteks penyelidikan penelitian kualitas pada kualitas layanan. Studi yang sama juga dilakukan oleh Parasuraman et al. (1988) yang menyelidiki kualitas secara spesifik dalam konteks pelayanan jasa. Sejak saat itu, konseptualisasi dan pengukuran kualitas jasa menjadi isu penting dalam konteks riset pemasaran jasa (Annamdevula dan Bellamkonda, 2016).

Beberapa peneliti sebelumnya sudah mencoba untuk mengadopsi model SERVQUAL untuk diaplikasikan pada konteks perguruan tinggi (Chua, 2004; Cuthbert, 1996a; Cuthbert, 1996b). Berbagai kritik bermunculan mengenai relevansi penerapan model SERVQUAL ketika diaplikasikan pada konteks perguruan tinggi. Kritik aplikasi model generik SERVQUAL ini pada akhirnya memunculkan model-model alternatif pengukuran kualitas layanan. Abdullah (2006) mengusulkan model HEdPERF (Higher Education PERformance). Abdullah (2006) mengembangkan skala HEdPERF yang terdiri atas 41 item pengukuran. Item pengukuran HedPERF telah secara empiris diuji unidimensionalitas, reliabilitas, dan validitas menggunakan gabungan antara 
exploratory dan confirmatory factor analysis (CFA). Abdullah (2006) menyatakan bahwa skala HedPERF berguna bagi perguruan tinggi untuk meningkatkan kinerja layanan di tengah kompetisi persaingan yang ketat di pasar global.

Tabel 1. Skala Pengukuran HedPERF

\begin{tabular}{|c|c|c|}
\hline Variable & Dimensions & Items Measurement \\
\hline $\begin{array}{c}\text { Higher Education } \\
\text { Performance } \\
\text { (HedPERF) merupakan } \\
\text { instrument } \\
\text { pengukuran baru } \\
\text { kualitas layanan yang } \\
\text { berupaya untuk } \\
\text { menangkap } \\
\text { determinan autentik } \\
\text { dari kualitas layanan di } \\
\text { sektor pendidikan } \\
\text { tinggi } \\
\text { (Abdullah, 2006). }\end{array}$ & $\begin{array}{c}\text { Aspek Non-Akademis. Faktor } \\
\text { ini meliputi item penting } \\
\text { yang memungkinkan } \\
\text { mahasiswa memenuhi } \\
\text { kewajiban studi mereka. } \\
\text { Faktor ini juga berkaitan } \\
\text { dengan tugas dan tanggung } \\
\text { jawab staf non-akademik. }\end{array}$ & $\begin{array}{l}\text { 1. Niat yang tulus memecahkan masalah } \\
\text { 2. Kepedulian dan perhatian individual } \\
\text { 3. Efisien dan cepat dalam menangani } \\
\text { komplain } \\
\text { 4. Cepat tanggap terhadap mahasiswa } \\
\text { yang meminta bantuan } \\
\text { 5. Pencatatan yang akurat dan mudah } \\
\text { diakses } \\
\text { 6. Menepati janji } \\
\text { 7. Kenyamanan jam pelayanan } \\
\text { 8. Sikap yang positif } \\
\text { 9. Komunikasi yang baik } \\
\text { 10. Pengetahuan yang baik terhadap sistem } \\
\text { 11. Perasaan aman dan percaya } \\
\text { 12. Penyampaian layanan dalam waktu } \\
\text { 13. Perlakuan yang sama dan rasa hormat }\end{array}$ \\
\hline & $\begin{array}{l}\text { Aspek Akademis. Indikator } \\
\text { yang mengelompok pada } \\
\text { faktor ini hanya membahas } \\
\text { tanggung jawab dari staf } \\
\text { akademik }\end{array}$ & $\begin{array}{l}\text { 1. Pengetahuan yang baik materi } \\
\text { 2. Kerkuliahan } \\
\text { 3. Cepat tanggap terhadap mahasiswa } \\
\text { yang meminta bantuan } \\
\text { 4. Niat tulus memecahkan masalah } \\
\text { 5. Sikap yang positif } \\
\text { 6. Komunikasi yang baik } \\
\text { 7. Umpan balik tentang progress akademik } \\
\text { 8. Kenyamanan dan kemudahan konsultasi }\end{array}$ \\
\hline & $\begin{array}{l}\text { Reputasi. Indikator yang } \\
\text { membentuk faktor ini } \\
\text { menekankan pentingnya } \\
\text { lembaga pendidikan tinggi } \\
\text { memproyeksikan citra } \\
\text { professional. }\end{array}$ & $\begin{array}{l}\text { 1. Penampilan professional } \\
\text { 2. Fasilitas asrama dan peralatan } \\
\text { 3. Fasilitas akademik } \\
\text { 4. Program mutu internal } \\
\text { 5. Fasilitas rekreasi } \\
\text { 6. Standar ukuran kelas } \\
\text { 7. Lokasi kampus yang ideal } \\
\text { 8. Reputasi program yang terkemuka } \\
\text { 9. Kemudahan lulusan mendapatkan } \\
\text { pekerjaan }\end{array}$ \\
\hline & $\begin{array}{l}\text { Akses. Faktor ini berisikan } \\
\text { indikator yang berhubungan } \\
\text { dengan isu aksesibilitas, } \\
\text { kemudahan kontak, } \\
\text { ketersediaan, dan } \\
\text { kenyamanan }\end{array}$ & $\begin{array}{l}\text { 1. Kemudahan dihubungi melalui telepon } \\
\text { 2. Cukup banyak kebebasan } \\
\text { 3. Kerahasiaan infomasi } \\
\text { 4. Serikat mahasiswa } \\
\text { 5. Umpan balik untuk perbaikan } \\
\text { 6. Prosedur penyampaian layanan }\end{array}$ \\
\hline
\end{tabular}




\begin{tabular}{|c|c|c|}
\hline Variable & Dimensions & Items Measurement \\
\hline & $\begin{array}{l}\text { Isu Program. Faktor ini } \\
\text { menekankan pentingnya } \\
\text { menawarkan beragam } \\
\text { program dan spesialisasi } \\
\text { dengan silabus dan struktur } \\
\text { yang fleksibel. }\end{array}$ & $\begin{array}{l}\text { 1. Variasi program/spesialisasi } \\
\text { 2. Silabus dan struktur yang fleksibel }\end{array}$ \\
\hline & $\begin{array}{l}\text { Pemahaman. Faktor ini } \\
\text { meliputi bagaimana } \\
\text { memahami kebutuhan } \\
\text { spesifik mahasiswa dalam hal } \\
\text { counselling dan layanan } \\
\text { kesehatan. }\end{array}$ & $\begin{array}{l}\text { 1. Layanan konseling (counselling) } \\
\text { 2. Layanan kesehatan }\end{array}$ \\
\hline
\end{tabular}

\section{HiEduQual (Higher Education Quality)}

Selain skala pengukuran yang dikembangkan oleh Abdullah (2006), beberapa peneliti lainnya juga mencoba secara spesifik mengembangkan skala pengukuran kualitas layanan perguruan tinggi. Annamdevula dan Bellamkonda (2016) dalam studinya juga mengembangkan skala pengukuran baru kualitas layanan spesifik pada konteks perguruan tinggi. Annamdevula dan Bellamkonda (2016) mengembangkan skala pengukuran baru kualitas layanan yang kemudian mereka beri nama HiEduQual. Pengembangan skala pengukuran HiEduQual berawal dari serangkaian upaya pencarian in-depth literature review, focus group discussion, dan expert opinion. 42 dari 57 item pernyataan terkait dengan layanan yang diberikan oleh universitas dan mengukur kualitas layanan yang dipersepsikan oleh mahasiswa (Annamdevula dan Bellamkonda, 2016). Hasil purifikasi skala pengukuran HiEduQual melalui pengujian unidimensionality, reliabilitas, dan validitas, serta pengujian confirmatory factor analysis (CFA) menghasilkan 6 (enam) faktor baru dengan menyisakan hanya 31 item pengukuran. HiEduQual juga diyakini sebagai skala pengukuran yang terbukti valid untuk mengukur kualitas layanan spesifik pada konteks perguruan tinggi.

Tabel 2. Skala Pengukuran HiEduQual

\begin{tabular}{|c|c|c|}
\hline Variable & Dimensions & Items Measurement \\
\hline & Teaching & 1. Dosen responsif dan mudah ditemui \\
\hline & (Pengajaran) & $\begin{array}{l}\text { 2. Konten perkuliahan mengembangkan pengetahuan } \\
\text { siswa }\end{array}$ \\
\hline Higher Education & & 3. Dosen menerapkan praktek pembelajaran yang baik \\
\hline Quality & & 4. Dosen mengikuti kurikulum berlaku dengan baik \\
\hline (HiEduQual) & & 5. Dosen secara berkala mengevaluasi kemajuan belajar \\
\hline merupakan skala & & siswa \\
\hline pengukuran & & 6. Program studi memiliki staf akademik yang memadai \\
\hline $\begin{array}{l}\text { kualitas layanan } \\
\text { baru yang }\end{array}$ & & $\begin{array}{l}\text { 7. Dosen memperlakukan semua siswa dengan cara yang } \\
\text { sama }\end{array}$ \\
\hline $\begin{array}{l}\text { dikembang-kan } \\
\text { secara spesifik }\end{array}$ & & $\begin{array}{l}\text { 8. Dosen secara berkala meminta umpan balik } \\
\text { pembelajaran untuk memberikan pelayanan lebih baik }\end{array}$ \\
\hline
\end{tabular}




\begin{tabular}{|c|c|c|}
\hline Variable & Dimensions & Items Measurement \\
\hline \multirow[t]{5}{*}{$\begin{array}{l}\text { pada konteks } \\
\text { perguruan tinggi } \\
\text { (Annam-devula } \\
\text { dan Bellamkonda, } \\
\text { 2016) }\end{array}$} & $\begin{array}{l}\text { Administrative } \\
\text { Service } \\
\text { (Layanan } \\
\text { administratif) }\end{array}$ & $\begin{array}{l}\text { 1. Staf admin menyampaikan pelayanan yang bebas dari } \\
\text { kesalahan } \\
\text { 2. Staf admin menyampaikan pelayanan tanpa menunda } \\
\text { 3. Staf admin menunjukkan kesopanan dan kesediaan } \\
\text { untuk membantu } \\
\text { 4. Staf admin mengelola administrasi laporan dengan baik } \\
\text { 5. Staf admin mudah diakses selama jam kerja } \\
\text { 6. Siswa memperoleh kemudahan akses informasi }\end{array}$ \\
\hline & $\begin{array}{l}\text { Academic } \\
\text { Facilities } \\
\text { (Fasilitas } \\
\text { Akademik) }\end{array}$ & $\begin{array}{l}\text { 1. Ruangan kelas dilengkapi dengan fasilitas pembelajaran } \\
\text { 2. Laboratorium komputer tersedia dengan baik } \\
\text { 3. Perpustakaan memiliki sumber daya akademik memadai } \\
\text { 4. Perpustakaan dilengkapi dengan E-Library } \\
\text { 5. Lingkungan kampus memberikan kenyamanan untuk } \\
\text { belajar dengan baik } \\
\text { 6. Universitas memiliki auditorium } \\
\text { 7. Perawatan fasilitas yang baik }\end{array}$ \\
\hline & $\begin{array}{l}\text { Campus } \\
\text { Infrastructure } \\
\text { (Infrastruktur } \\
\text { Kampus) }\end{array}$ & $\begin{array}{l}\text { 1. Universitas memiliki fasilitas olah raga dan rekreasi } \\
\text { 2. Universitas memiliki fasilitas asrama } \\
\text { 3. Universitas memiliki standar keselamatan dan keamanan } \\
\text { 4. Hostel universitas memiliki standar kualitas makanan }\end{array}$ \\
\hline & $\begin{array}{c}\text { Support Service } \\
\text { (Layanan } \\
\text { Pendukung) }\end{array}$ & $\begin{array}{l}\text { 1. Universitas memiliki fasilitas yang memadai } \\
\text { 2. Universitas menyelenggarakan kegiatan budaya dan } \\
\text { ekstrakulikuler } \\
\text { 3. Universitas memberikan layanan konseling } \\
\text { 4. Universitas memberikan layanan kesehatan }\end{array}$ \\
\hline & $\begin{array}{l}\text { Inter- } \\
\text { nationalization } \\
\quad \text { (Inter- } \\
\text { nasionalisasi) }\end{array}$ & $\begin{array}{l}\text { 1. Universitas mempromosikan aktivitas internasionalisasi } \\
\text { 2. Universitas memiliki banyak dosen lulusan luar negeri }\end{array}$ \\
\hline
\end{tabular}

Sultan dan Wong (2012) mengemukakan bahwa ada urgensi pada konteks penyelidikan empiris dalam mengembangkan skala pengukuran yang lebih spesifik dalam mengukur kualitas layanan perguruan tinggi. Skala pengukuran yang dipergunakan pada sektor bisnis diyakini kurang relevan jika diadaptasikan pada konteks sektor publik, terutama pada konteks penyelidikan penelitian kualitas layanan di perguruan tinggi. Oleh karena itu, penelitian ini berupaya untuk menyaring berbagai item pengukuran spesifik kualitas layanan perguruan tinggi di dalam literatur.

\section{METODE PENELITIAN}

Jenis penelitian ini adalah penelitian deskriptif kuantitatif, yang bertujuan untuk memberikan gambaran yang utuh dan menyeluruh dari suatu fenomena yang menjadi fokus pengamatan penelitian (Cooper dan Schindler, 2006). Studi ini hanya akan dilakukan pada satu waktu tertentu yang akan menunjukkan suatu potret fenomena untuk menjawab pertanyaan yang akan diteliti sehingga menggunakan desain crosssectional (Neuman, 2006, h.36; Cooper dan Schindler, 2011, h.142). Metode yang digunakan dalam studi ini adalah survei yang menggunakan kuisioner dengan menggunakan banyak sumber data sebagai dasar untuk menganalisis dan membuat kesimpulan (Neuman, 2006, h.273). Strategi survei digunakan karena sesuai untuk 
pertanyaan penelitian tentang self-reported belief atau perilaku (Neuman, 2006, h.273). Potret fenomena yang ingin untuk diungkapkan dalam penelitian ini adalah persepsi mahasiswa mengenai kualitas layanan di Fakultas Ekonomi dan Bisnis Universitas Bengkulu (FEB UniB).

Penarikan sampel dalam penelitian ini dilakukan secara acak (probability sampling) dengan teknik sampling acak berlapis (stratified random sampling) dalam memperoleh informasi dari responden. Startified random sampling merupakan teknik sampling yang membagi populasi menjadi dua segmen atau lebih yang muatually exclusive yang disebut starta/stratum, berdasarkan kategori-kategori (Rahmatina, 2010). Jumlah sampel yang digunakan adalah 200 orang, terdiri dari mahasiswa angkatan 2013, 2014, 2015, 2016 yang berasal dari masing-masing jurusan yang ada di FEB UniB pada jenjang SO dan S1. Jurusan yang ada di FEB UniB meliputi jurusan Akuntansi, jurusan Manajemen dan jurusan Ekonomi Pembangunan, dengan jumlah sampel masing-masing angkatan dan jurusan adalah 15 orang. Ditambahkan dengan 3 angkatan dari jurusan D3 Akuntansi dengan masing-masing sampel per angkatan 15. Kelebihan sampel dijadikan cadangan untuk mengantisipasi data yang tidak valid.

Sumber data penelitian ini adalah data primer. Data primer merupakan data yang berasal dari sumber asli atau pertama yang harus dicari melalui responden (Sarwono, 2006: 129). Data primer dalam diperoleh melalui survei. Survei yang dilakukan dalam penelitian ini adalah online survei melalui fasilitas Google-Forms. Google Forms adalah aplikasi dari akun google yang bersifat umum dan dapat diakses gratis jika memiliki akun google. Rancangan kuisioner online yang telah disusun menggunakan Google Forms diupload ke dalam google drive agar dapat diakses secara umum. Responden target penelitian diundang secara resmi melalui perwakilan mahasiswa dari masing-masing jurusan untuk mengisi kuisioner online melalui fasilitas laboratorium komputer yang ada di FEB UniB. Karena keterbatasan fasilitas komputer yang tersedia, mahasiswa diatur berpartisipasi dalam kegiatan survei di Lab-komputer secara bergantian dengan menyusun time schedule mekanisme survei secara tersruktur selama tiga hari kegiatan. Survei online yang dilakukan diyakini menjadi metode yang lebih efektif jika dibandingkan dengan mekanisme survei konvensional.

Metode analisis data yang digunakan dalam penelitian ini, adalah metode statistik deskriptif. Analisis deskriptif adalah analisis data dengan menggunakan statistik-statistik univariate seperti mencari nilai rata-rata (mean), nilai tengah (median), nilai yang paling banyak muncul (modus), deviasi standar, varians, dan lainlain. Penelitian ini menggunakan kuisioner sebagai alat pengumpulan data. Item pernyataan di dalam kuisioner di ukur dengan menggunakan Skala Likert. Data yang diperoleh ditabulasi menggunakan Microsoft excel untuk kemudian di olah menggunakan SPSS 16.0. Item pertanyaan penelitian dianalisis dengan menggunakan analisis deskriptif dengan pendekatan distribusi frekuensi. Distribusi frekuensi akan menghasilkan tabel hitungan frekuensi, persentase, dan persentase komulatif untuk seluruh nilai yang diasosiasikan dengan variabel. 


\section{HASIL PENELITIAN}

Dalam penelitian ini, terdapat 55 indikator dari kualitas layanan yang berasal dari beberapa dimensi. Dengan menggunakan analisis faktor, peneliti membagi beberapa dimensi yang membentuk kualitas layanan yang diberikan FEB Unib. Hasil analisis menemukan outlier yang berasal dari 8 indikator. Sehingga dalam penelitian ini hanya digunakan 47 indikator. 47 indikator ini kemudian diolah sehingga membentuk 6 dimensi yang terdiri dari:

\section{Faktor 1: Layanan Administratif (Administrative Service)}

Faktor 1 dibentuk dari delapan belas indikator. Distribusi respon responden terhadap delapan belas indikator tersebut tersaji pada Tabel 3. Faktor 1 sesuai untuk diberi nama layanan administratif yang dibentuk oleh indikator-indikator yang berkaitan dengan layanan yang diberikan oleh karyawan FEB Unib.

Tabel 3. Layanan Administratif (Administrative Service)

\begin{tabular}{|c|c|c|c|c|c|c|c|c|}
\hline \multirow[t]{2}{*}{ No } & \multirow[t]{2}{*}{ Pernyataan } & \multicolumn{6}{|c|}{ Tanggapan Responden } & \multirow[t]{2}{*}{ Jumlah } \\
\hline & & STS & TS & KS & CS & $\mathbf{S}$ & SS & \\
\hline 1. & $\begin{array}{l}\text { FEB Unib memberikan pelayanan yang } \\
\text { baik kepada mahasiswa. }\end{array}$ & $\begin{array}{c}1 \\
(0,5 \%)\end{array}$ & $\begin{array}{c}10 \\
(4,6 \%)\end{array}$ & $\begin{array}{c}36 \\
(16,4 \%)\end{array}$ & $\begin{array}{c}75 \\
(34,2 \%)\end{array}$ & $\begin{array}{c}70 \\
(32 \%)\end{array}$ & $\begin{array}{c}27 \\
(12,3 \%)\end{array}$ & $\begin{array}{c}219 \\
(100 \%)\end{array}$ \\
\hline 2. & $\begin{array}{l}\text { FEB Unib memberikan pelayanan yang } \\
\text { detail dari awal mahasiswa menduduki } \\
\text { bangku kuliah }\end{array}$ & $\begin{array}{c}3 \\
(1,4 \%)\end{array}$ & $\begin{array}{c}11 \\
(5 \%)\end{array}$ & $\begin{array}{c}50 \\
(22,8 \%)\end{array}$ & $\begin{array}{c}64 \\
(29,2 \%)\end{array}$ & $\begin{array}{c}55 \\
(25,1 \%)\end{array}$ & $\begin{array}{c}36 \\
(16,4 \%)\end{array}$ & $\begin{array}{c}219 \\
(100 \%)\end{array}$ \\
\hline 3. & $\begin{array}{l}\text { Karyawan FEB Unib menyampaikan } \\
\text { layanan kepada kami dengan cepat. }\end{array}$ & $\begin{array}{c}5 \\
(2,3 \%)\end{array}$ & $\begin{array}{c}22 \\
(10 \%)\end{array}$ & $\begin{array}{c}55 \\
(25,1 \%)\end{array}$ & $\begin{array}{c}67 \\
(30,6 \%)\end{array}$ & $\begin{array}{c}52 \\
(23,7 \%)\end{array}$ & $\begin{array}{c}18 \\
(8,2 \%)\end{array}$ & $\begin{array}{c}219 \\
(100 \%)\end{array}$ \\
\hline 4. & $\begin{array}{l}\text { Karyawan FEB Unib menyampaikan } \\
\text { layanan kepada kami tepat waktu. }\end{array}$ & $\begin{array}{c}6 \\
(2,7 \%)\end{array}$ & $\begin{array}{c}15 \\
(6,8 \%)\end{array}$ & $\begin{array}{c}59 \\
(26,9 \%)\end{array}$ & $\begin{array}{c}62 \\
(21,9 \%)\end{array}$ & $\begin{array}{c}59 \\
(26,9 \%)\end{array}$ & $\begin{array}{c}18 \\
(8,2 \%)\end{array}$ & $\begin{array}{c}219 \\
(100 \%)\end{array}$ \\
\hline 5. & $\begin{array}{l}\text { Karyawan di FEB Unib dengan senang } \\
\text { hati membantu kami dalam proses } \\
\text { akademik. }\end{array}$ & $\begin{array}{c}2 \\
(0,9 \%)\end{array}$ & $\begin{array}{c}13 \\
(5,9 \%)\end{array}$ & $\begin{array}{c}38 \\
(17,4 \%)\end{array}$ & $\begin{array}{c}67 \\
(30,6 \%)\end{array}$ & $\begin{array}{c}66 \\
(30,1 \%)\end{array}$ & $\begin{array}{c}33 \\
(15,1 \%)\end{array}$ & $\begin{array}{c}219 \\
(100 \%)\end{array}$ \\
\hline 6. & $\begin{array}{l}\text { Karyawan di FEB Unib melayani kami } \\
\text { dengan penuh kepedulian }\end{array}$ & $\begin{array}{c}5 \\
(2,3 \%)\end{array}$ & $\begin{array}{c}16 \\
(7,3 \%)\end{array}$ & $\begin{array}{c}55 \\
(25,4 \%)\end{array}$ & $\begin{array}{c}69 \\
(31,5 \%)\end{array}$ & $\begin{array}{c}58 \\
(26,5 \%)\end{array}$ & $\begin{array}{c}16 \\
(7,3 \%)\end{array}$ & $\begin{array}{c}219 \\
(100 \%)\end{array}$ \\
\hline 7. & $\begin{array}{l}\text { Karyawan di FEB Unib merespon } \\
\text { keluhan kami dengan cepat }\end{array}$ & $\begin{array}{c}5 \\
(2,3 \%)\end{array}$ & $\begin{array}{c}28 \\
(12,8 \%)\end{array}$ & $\begin{array}{c}61 \\
(27,9 \%)\end{array}$ & $\begin{array}{c}63 \\
(28,8 \%)\end{array}$ & $\begin{array}{c}42 \\
(19,2 \%)\end{array}$ & $\begin{array}{c}20 \\
(9,1 \%)\end{array}$ & $\begin{array}{c}219 \\
(100 \%)\end{array}$ \\
\hline 8 & $\begin{array}{l}\text { Karyawan di FEB Unib umumnya } \\
\text { memiliki riwayat pendidikan yang } \\
\text { bagus }\end{array}$ & $\begin{array}{c}0 \\
(0 \%)\end{array}$ & $\begin{array}{c}3 \\
(1,4 \%)\end{array}$ & $\begin{array}{c}30 \\
(13,7 \%)\end{array}$ & $\begin{array}{c}44 \\
(20,1 \%)\end{array}$ & $\begin{array}{c}103 \\
(47 \%)\end{array}$ & $\begin{array}{c}39 \\
(17,8 \%)\end{array}$ & $\begin{array}{c}219 \\
(100 \%)\end{array}$ \\
\hline 9. & $\begin{array}{l}\text { Karyawan di FEB Unib menunjukkan } \\
\text { kesopanan kepada kami dalam } \\
\text { menyampaikan layanan. }\end{array}$ & $\begin{array}{c}3 \\
(1,4 \%)\end{array}$ & $\begin{array}{c}14 \\
(6,4 \%)\end{array}$ & $\begin{array}{c}37 \\
(16,9 \%)\end{array}$ & $\begin{array}{c}67 \\
(30,6 \%)\end{array}$ & $\begin{array}{c}68 \\
(31,1 \%)\end{array}$ & $\begin{array}{c}30 \\
(13,7 \%)\end{array}$ & $\begin{array}{c}219 \\
(100 \%)\end{array}$ \\
\hline 10. & $\begin{array}{l}\text { Karyawan di FEB Unib mampu } \\
\text { menumbuhkan kepercayaan di hati } \\
\text { dalam menyampaikan layanan. }\end{array}$ & $\begin{array}{c}1 \\
(0,5 \%)\end{array}$ & $\begin{array}{c}16 \\
(7,3 \%)\end{array}$ & $\begin{array}{c}56 \\
(25,6 \%)\end{array}$ & $\begin{array}{c}66 \\
(30,1 \%)\end{array}$ & $\begin{array}{c}59 \\
(26,9 \%)\end{array}$ & $\begin{array}{c}21 \\
(9,6 \%)\end{array}$ & $\begin{array}{c}219 \\
(100 \%)\end{array}$ \\
\hline 11. & $\begin{array}{l}\text { Karyawan di FEB Unib mampu } \\
\text { memberikan kami keyakinan dalam } \\
\text { menyampaikan layanan. }\end{array}$ & $\begin{array}{c}0 \\
(0 \%)\end{array}$ & $\begin{array}{c}13 \\
(5,9 \%)\end{array}$ & $\begin{array}{c}53 \\
(24,2 \%)\end{array}$ & $\begin{array}{c}71 \\
(32,4 \%)\end{array}$ & $\begin{array}{c}56 \\
(25,6 \%)\end{array}$ & $\begin{array}{c}26 \\
(11,9 \%)\end{array}$ & $\begin{array}{c}219 \\
(100 \%)\end{array}$ \\
\hline 12. & $\begin{array}{l}\text { Karyawan di FEB Unib bersikap ramah } \\
\text { dan sopan kepada mahasiswa. }\end{array}$ & $\begin{array}{c}2 \\
(0,9 \%)\end{array}$ & $\begin{array}{c}16 \\
(7,3 \%)\end{array}$ & $\begin{array}{c}43 \\
(19,6 \%)\end{array}$ & $\begin{array}{c}62 \\
(28,3 \%)\end{array}$ & $\begin{array}{c}65 \\
(29,7 \%)\end{array}$ & $\begin{array}{c}31 \\
(14,2 \%)\end{array}$ & $\begin{array}{c}219 \\
(100 \%)\end{array}$ \\
\hline 13. & $\begin{array}{l}\text { Karyawan di FEB Unib menunjukkan } \\
\text { kepedulian. }\end{array}$ & $\begin{array}{c}1 \\
(0,5 \%)\end{array}$ & $\begin{array}{c}20 \\
(9,1 \%)\end{array}$ & $\begin{array}{c}40 \\
(18,3 \%)\end{array}$ & $\begin{array}{c}75 \\
(34,2 \%)\end{array}$ & $\begin{array}{c}56 \\
(25,6 \%)\end{array}$ & $\begin{array}{c}27 \\
(12,3 \%)\end{array}$ & $\begin{array}{c}219 \\
(100 \%)\end{array}$ \\
\hline 14. & $\begin{array}{l}\text { Karyawan FEB Unib memberikan akses } \\
\text { yang mudah kepada kami pada }\end{array}$ & $\begin{array}{c}1 \\
(0,5 \%)\end{array}$ & $\begin{array}{c}13 \\
(5,9 \%)\end{array}$ & $\begin{array}{c}39 \\
(17,8 \%)\end{array}$ & $\begin{array}{c}72 \\
(32,9 \%)\end{array}$ & $\begin{array}{c}64 \\
(29,2 \%)\end{array}$ & $\begin{array}{c}30 \\
(13,7 \%)\end{array}$ & $\begin{array}{c}219 \\
(100 \%)\end{array}$ \\
\hline
\end{tabular}




\begin{tabular}{|c|c|c|c|c|c|c|c|c|}
\hline \multirow[t]{2}{*}{ No } & \multirow[t]{2}{*}{ Pernyataan } & \multicolumn{6}{|c|}{ Tanggapan Responden } & \multirow[t]{2}{*}{ Jumlah } \\
\hline & & STS & TS & KS & CS & $\mathbf{S}$ & SS & \\
\hline & berbagai layanan pendidikan. & & & & & & & \\
\hline 15. & $\begin{array}{l}\text { Karyawan di FEB Unib memiliki } \\
\text { kecakapan dalam berkomunikasi. }\end{array}$ & $\begin{array}{c}1 \\
(0,5 \%)\end{array}$ & $\begin{array}{c}12 \\
(5,5 \%)\end{array}$ & $35(16 \%)$ & $\begin{array}{c}72 \\
(32,9 \%)\end{array}$ & $\begin{array}{c}67 \\
(30,6 \%)\end{array}$ & $\begin{array}{c}32 \\
(14,6 \%)\end{array}$ & $\begin{array}{c}219 \\
(100 \%)\end{array}$ \\
\hline 16. & $\begin{array}{l}\text { Karyawan di FEB Unib mampu } \\
\text { memberikan perhatian personal } \\
\text { kepada kami. }\end{array}$ & $\begin{array}{c}3 \\
(1,4 \%)\end{array}$ & $\begin{array}{c}25 \\
(11,4 \%)\end{array}$ & $\begin{array}{c}59 \\
(26,9 \%)\end{array}$ & $\begin{array}{c}71 \\
(32,4 \%)\end{array}$ & $\begin{array}{c}49 \\
(22,4 \%)\end{array}$ & $\begin{array}{c}12 \\
(5,5 \%)\end{array}$ & $\begin{array}{c}219 \\
(100 \%)\end{array}$ \\
\hline 17 & $\begin{array}{l}\text { Karyawan di FEB Unib mampu } \\
\text { memberikan pemahaman yang } \\
\text { dimudah dimengerti kepada kami. }\end{array}$ & $\begin{array}{c}0 \\
(0 \%)\end{array}$ & $\begin{array}{c}11 \\
(5 \%)\end{array}$ & $\begin{array}{c}38 \\
(17,4 \%)\end{array}$ & $\begin{array}{c}81 \\
(37 \%)\end{array}$ & $\begin{array}{c}66 \\
(30,1 \%)\end{array}$ & $\begin{array}{c}23 \\
(10,5 \%)\end{array}$ & $\begin{array}{c}219 \\
(100 \%)\end{array}$ \\
\hline 18 & $\begin{array}{l}\text { Karyawan selalu berada di tempat } \\
\text { ketika kami membutuhkannya. }\end{array}$ & $\begin{array}{c}17 \\
(7,8 \%)\end{array}$ & $\begin{array}{c}34 \\
(15,5 \%)\end{array}$ & $\begin{array}{c}60 \\
(27,4 \%)\end{array}$ & $\begin{array}{c}53 \\
(24,2 \%)\end{array}$ & $\begin{array}{c}41 \\
(18,7 \%)\end{array}$ & $\begin{array}{c}14 \\
(6,4 \%)\end{array}$ & $\begin{array}{c}219 \\
(100 \%)\end{array}$ \\
\hline
\end{tabular}

Sumber: Data Primer (2019)

\section{Faktor 2: Sarana dan Prasarana}

Faktor 2 dibentuk dari dua belas indikator. Faktor 2 sangat sesuai dinamai sarana dan prasarana karena dibentuk dari indikator-indikator mengenai fasilitas sarana dan prasarana yang ada di FEB Unib. Distribusi respon responden terhadap dua belas indikator tersebut tersaji pada Tabel 4.

Tabel 4. Sarana dan Prasarana

\begin{tabular}{|c|c|c|c|c|c|c|c|c|}
\hline \multirow[t]{2}{*}{ No } & \multirow[t]{2}{*}{ Pernyataan } & \multicolumn{6}{|c|}{ Tanggapan Responden } & \multirow[t]{2}{*}{ Jumlah } \\
\hline & & STS & TS & KS & CS & $\mathbf{S}$ & SS & \\
\hline 1. & $\begin{array}{l}\text { FEB Unib memiliki fasilitas layanan } \\
\text { yang baik. }\end{array}$ & $\begin{array}{c}7 \\
(3,2 \%)\end{array}$ & $\begin{array}{c}21 \\
(9,6 \%)\end{array}$ & $\begin{array}{c}37 \\
(16,9 \%)\end{array}$ & $\begin{array}{c}62 \\
(28,3 \%)\end{array}$ & $\begin{array}{c}64 \\
(29,2 \%)\end{array}$ & $\begin{array}{c}28 \\
(12,8 \%)\end{array}$ & $\begin{array}{c}219 \\
(100 \%)\end{array}$ \\
\hline 2. & $\begin{array}{l}\text { FEB Unib memiliki } \\
\text { peralatan/perlengkapan yang } \\
\text { memadai. }\end{array}$ & $\begin{array}{c}11 \\
(5 \%)\end{array}$ & $\begin{array}{c}22 \\
(10 \%)\end{array}$ & $\begin{array}{c}45 \\
(20,5 \%)\end{array}$ & $\begin{array}{c}59 \\
(26,9 \%)\end{array}$ & $\begin{array}{c}50 \\
(22,8 \%)\end{array}$ & $\begin{array}{c}32 \\
(14,6 \%)\end{array}$ & $\begin{array}{c}219 \\
(100 \%)\end{array}$ \\
\hline 3. & $\begin{array}{l}\text { Ruang belajar di FEB Unib terasa } \\
\text { nyaman. }\end{array}$ & $\begin{array}{c}24 \\
(11 \%)\end{array}$ & $\begin{array}{c}28 \\
(12,8 \%)\end{array}$ & $\begin{array}{c}46 \\
(21 \%)\end{array}$ & $\begin{array}{c}49 \\
(22,4 \%)\end{array}$ & $\begin{array}{c}51 \\
(23,3 \%)\end{array}$ & $\begin{array}{c}21 \\
(9,6 \%)\end{array}$ & $\begin{array}{c}219 \\
(100 \%)\end{array}$ \\
\hline 4. & $\begin{array}{l}\text { Ruang layanan akademik di FEB Unib } \\
\text { terasa nyaman. }\end{array}$ & $\begin{array}{c}6 \\
(2,7 \%)\end{array}$ & $\begin{array}{c}20 \\
(9,1 \%)\end{array}$ & $\begin{array}{c}38 \\
(17,4 \%)\end{array}$ & $\begin{array}{c}63 \\
(28,8 \%)\end{array}$ & $\begin{array}{c}57 \\
(26 \%)\end{array}$ & $\begin{array}{c}35 \\
(16 \%)\end{array}$ & $\begin{array}{c}219 \\
(100 \%)\end{array}$ \\
\hline 5. & $\begin{array}{l}\text { Fasilitas gedung di FEB Unib terlihat } \\
\text { menarik. }\end{array}$ & $\begin{array}{c}22 \\
(10 \%)\end{array}$ & $\begin{array}{c}33 \\
(15,1 \%)\end{array}$ & $\begin{array}{c}47 \\
(21,5 \%)\end{array}$ & $\begin{array}{c}57 \\
(26 \%)\end{array}$ & $\begin{array}{c}39 \\
(17,8 \%)\end{array}$ & $\begin{array}{c}21 \\
(9,6 \%)\end{array}$ & $\begin{array}{c}219 \\
(100 \%)\end{array}$ \\
\hline 6. & $\begin{array}{l}\text { Peralatan penunjang perkuliahan di } \\
\text { FEB Unib sangat memadai. }\end{array}$ & $\begin{array}{c}10 \\
(4,6 \%)\end{array}$ & $\begin{array}{c}31 \\
(14,2 \%)\end{array}$ & $\begin{array}{c}48 \\
(21,9 \%)\end{array}$ & $\begin{array}{c}66 \\
(30,1 \%)\end{array}$ & $\begin{array}{c}43 \\
(19,6 \%)\end{array}$ & $\begin{array}{c}21 \\
(9,6 \%)\end{array}$ & $\begin{array}{c}219 \\
(100 \%)\end{array}$ \\
\hline 7. & $\begin{array}{l}\text { Fasilitas sarana dan prasarana di FEB } \\
\text { Unib sangat memadai. }\end{array}$ & $\begin{array}{c}12 \\
(5,5 \%)\end{array}$ & $\begin{array}{c}32 \\
(14,6 \%)\end{array}$ & $\begin{array}{c}47 \\
(21,5 \%)\end{array}$ & $\begin{array}{c}67 \\
(30,6 \%)\end{array}$ & $\begin{array}{c}43 \\
(19,6 \%)\end{array}$ & $\begin{array}{c}18 \\
(8,2 \%)\end{array}$ & $\begin{array}{c}219 \\
(100 \%)\end{array}$ \\
\hline 8. & $\begin{array}{l}\text { Ruang perpustakaan di FEB Unib } \\
\text { terasa nyaman. }\end{array}$ & $\begin{array}{c}8 \\
(3,7 \%)\end{array}$ & $\begin{array}{c}17 \\
(7,8 \%)\end{array}$ & $\begin{array}{c}36 \\
(16,4 \%)\end{array}$ & $\begin{array}{c}69 \\
(31,5 \%)\end{array}$ & $\begin{array}{c}60 \\
(27,4 \%)\end{array}$ & $\begin{array}{c}29 \\
(13,2 \%)\end{array}$ & $\begin{array}{c}219 \\
(100 \%)\end{array}$ \\
\hline 9. & $\begin{array}{l}\text { Peralatan komputer di laboratorium } \\
\text { sangat memadai. }\end{array}$ & $\begin{array}{c}12 \\
(5,5 \%)\end{array}$ & $\begin{array}{c}18 \\
(8,2 \%)\end{array}$ & $\begin{array}{c}39 \\
(17,8 \%)\end{array}$ & $\begin{array}{c}68 \\
(31,1 \%)\end{array}$ & $\begin{array}{c}62 \\
(28,3 \%)\end{array}$ & $\begin{array}{c}20 \\
(9,1 \%)\end{array}$ & $\begin{array}{c}219 \\
(100 \%)\end{array}$ \\
\hline 10. & $\begin{array}{l}\text { Kami merasa biaya UKT di FEB Unib } \\
\text { sudah sesuai dengan sarana dan } \\
\text { prasarana yang tersedia. }\end{array}$ & $\begin{array}{c}34 \\
(15,5 \%)\end{array}$ & $\begin{array}{c}46 \\
(21 \%)\end{array}$ & $\begin{array}{c}40 \\
(18,3 \%)\end{array}$ & $\begin{array}{c}47 \\
(21,5 \%)\end{array}$ & $\begin{array}{c}32 \\
(14,6 \%)\end{array}$ & $\begin{array}{c}20 \\
(9,1 \%)\end{array}$ & $\begin{array}{c}219 \\
(100 \%)\end{array}$ \\
\hline 11. & $\begin{array}{l}\text { Kami merasa anggaran di FEB Unib } \\
\text { sudah dialokasikan dengan benar. }\end{array}$ & $\begin{array}{c}15 \\
(6,8 \%)\end{array}$ & $\begin{array}{c}34 \\
(15,5 \%)\end{array}$ & $\begin{array}{c}48 \\
(21,9 \%)\end{array}$ & $\begin{array}{c}64 \\
(29,2 \%)\end{array}$ & $\begin{array}{c}45 \\
(20,5 \%)\end{array}$ & $\begin{array}{c}13 \\
(5,9 \%)\end{array}$ & $\begin{array}{c}219 \\
(100 \%)\end{array}$ \\
\hline 12. & $\begin{array}{l}\text { Fasilitas jaringan internet di FEB Unib } \\
\text { sangat baik. }\end{array}$ & $\begin{array}{c}31 \\
(14,2 \%)\end{array}$ & $\begin{array}{c}44 \\
(20,1 \%)\end{array}$ & $\begin{array}{c}44 \\
(20,1 \%)\end{array}$ & $\begin{array}{c}49 \\
(22,4 \%)\end{array}$ & $\begin{array}{c}38 \\
(17,4 \%)\end{array}$ & $\begin{array}{c}13 \\
(5,9 \%)\end{array}$ & $\begin{array}{c}219 \\
(100 \%)\end{array}$ \\
\hline
\end{tabular}

Sumber: Data Primer (2019) 


\section{Faktor 3: Kualitas Pengajaran (Teaching Quality)}

Faktor 3 dibentuk dari delapan indikator. Distribusi respon responden terhadap delapan indikator tersebut tersaji pada Tabel 5. Faktor 3 merupakan dimensi yang menyatakan tentang kualitas pengajaran (teaching quality) oleh dosen yang ada di FEB Unib.

Tabel 5. Kualitas Pengajaran (Teaching Quality)

\begin{tabular}{|c|c|c|c|c|c|c|c|c|}
\hline \multirow[t]{2}{*}{ No } & \multirow[t]{2}{*}{ Pernyataan } & \multicolumn{6}{|c|}{ Tanggapan Responden } & \multirow[t]{2}{*}{ Jumlah } \\
\hline & & STS & TS & KS & CS & $S$ & SS & \\
\hline 1. & $\begin{array}{l}\text { Dosen menerapkan } \\
\text { pembelajaran yang baik }\end{array}$ & $\begin{array}{c}1 \\
(0,5 \%)\end{array}$ & $\begin{array}{c}4 \\
(1,8 \%)\end{array}$ & $\begin{array}{c}36 \\
(16,4 \%)\end{array}$ & $\begin{array}{l}67 \\
(36 \%)\end{array}$ & $\begin{array}{c}78 \\
(35,6 \%)\end{array}$ & $\begin{array}{c}33 \\
(15,1 \%)\end{array}$ & $\begin{array}{c}219 \\
(100 \%)\end{array}$ \\
\hline 2. & $\begin{array}{l}\text { Dosen memiliki pengetahuan yang } \\
\text { baik terhadap sistem dan prosedur } \\
\text { yang berlaku }\end{array}$ & $\begin{array}{c}1 \\
(0,5 \%)\end{array}$ & $\begin{array}{c}4 \\
(1,8 \%)\end{array}$ & $\begin{array}{c}16 \\
(7,3 \%)\end{array}$ & $\begin{array}{c}57 \\
(26 \%)\end{array}$ & $\begin{array}{c}96 \\
(43,8 \%)\end{array}$ & $\begin{array}{c}45 \\
(20,5 \%)\end{array}$ & $\begin{array}{c}219 \\
(100 \%)\end{array}$ \\
\hline 3. & $\begin{array}{l}\text { Dosen memiliki pengetahuan yang } \\
\text { baik terhadap materi perkuliahan }\end{array}$ & $\begin{array}{c}0 \\
(0 \%)\end{array}$ & $\begin{array}{c}2 \\
(0,9 \%)\end{array}$ & $\begin{array}{c}11 \\
(5 \%)\end{array}$ & $\begin{array}{c}50 \\
(22,8 \%)\end{array}$ & $\begin{array}{l}103 \\
(47 \%)\end{array}$ & $\begin{array}{c}53 \\
(24,2 \%)\end{array}$ & $\begin{array}{c}219 \\
(100 \%)\end{array}$ \\
\hline 4. & $\begin{array}{l}\text { Dosen mengikuti kurikulum yang } \\
\text { berlaku dengan baik }\end{array}$ & $\begin{array}{c}0 \\
(0 \%)\end{array}$ & $\begin{array}{c}4 \\
(1,8 \%)\end{array}$ & $\begin{array}{c}16 \\
(7,3 \%)\end{array}$ & $\begin{array}{c}58 \\
(26,5 \%)\end{array}$ & $\begin{array}{c}100 \\
(45,7 \%)\end{array}$ & $\begin{array}{c}41 \\
(18,7 \%)\end{array}$ & $\begin{array}{c}219 \\
(100 \%)\end{array}$ \\
\hline 5. & $\begin{array}{l}\text { Dosen memberikan silabus yang } \\
\text { fleksibel }\end{array}$ & $\begin{array}{c}2 \\
(0,9 \%)\end{array}$ & $\begin{array}{c}5 \\
(2,3 \%)\end{array}$ & $\begin{array}{c}24 \\
(11 \%)\end{array}$ & $\begin{array}{c}60 \\
(27,4 \%)\end{array}$ & $\begin{array}{c}84 \\
(38,4 \%)\end{array}$ & $\begin{array}{c}44 \\
(20,1 \%)\end{array}$ & $\begin{array}{c}219 \\
(100 \%)\end{array}$ \\
\hline 6. & $\begin{array}{l}\text { Dosen secara berkala mengevaluasi } \\
\text { kemajuan belajar mahasiswa }\end{array}$ & $\begin{array}{c}3 \\
(1,4 \%)\end{array}$ & $\begin{array}{c}14 \\
(6,4 \%)\end{array}$ & $\begin{array}{c}37 \\
(16,9 \%)\end{array}$ & $\begin{array}{c}76 \\
(34,7 \%)\end{array}$ & $\begin{array}{c}66 \\
(30,1 \%)\end{array}$ & $\begin{array}{c}23 \\
(10,5 \%)\end{array}$ & $\begin{array}{c}219 \\
(100 \%)\end{array}$ \\
\hline 7. & $\begin{array}{l}\text { Dosen secara berkala meminta } \\
\text { umpan balik pembelajaran untuk } \\
\text { memberikan pelayanan } \\
\text { (pembelajaran) lebih baik. }\end{array}$ & $\begin{array}{c}0 \\
(0 \%)\end{array}$ & $\begin{array}{c}7 \\
(3,2 \%)\end{array}$ & $\begin{array}{c}36 \\
(16,4 \%)\end{array}$ & $\begin{array}{c}71 \\
(32,4 \%)\end{array}$ & $\begin{array}{c}81 \\
(37 \%)\end{array}$ & $\begin{array}{c}24 \\
(11 \%)\end{array}$ & $\begin{array}{c}219 \\
(100 \%)\end{array}$ \\
\hline 8. & Dosen berpenampilan profesional & $\begin{array}{c}0 \\
(0 \%)\end{array}$ & $\begin{array}{c}2 \\
(0,9 \%)\end{array}$ & $\begin{array}{c}12 \\
(5,5 \%)\end{array}$ & $\begin{array}{c}56 \\
(25,6 \%)\end{array}$ & $\begin{array}{c}87 \\
(39,7 \%)\end{array}$ & $\begin{array}{c}62 \\
(28,3 \%)\end{array}$ & $\begin{array}{c}219 \\
(100 \%)\end{array}$ \\
\hline
\end{tabular}

Sumber: Data Primer (2019)

\section{Faktor 4: Pengalokasian Sumber Daya (Allocation of Resources)}

Faktor 4 dibentuk oleh tujuh indikator. Distribusi respon responden terhadap tujuh indikator tersebut tersaji pada Tabel 6. Faktor 4 merupakan salah satu dimensi dari kualitas layanan yang berhubungan dengan pengalokasian sumber daya (allocation of resources) di FEB Unib baik untuk karyawan FEB Unib maupun mahasiswa FEB Unib.

Tabel 6. Pengalokasian Sumber Daya (Allocation of Resources)

\begin{tabular}{|c|c|c|c|c|c|c|c|c|}
\hline \multirow[t]{2}{*}{ No } & \multirow[t]{2}{*}{ Pernyataan } & \multicolumn{6}{|c|}{ Tanggapan Responden } & \multirow[t]{2}{*}{ Jumlah } \\
\hline & & STS & TS & KS & CS & $\mathbf{S}$ & SS & \\
\hline 1. & $\begin{array}{l}\text { Pihak Fakultas menyediakan alokasi } \\
\text { anggaran yang memadai dalam } \\
\text { mendukung kegiatan kemahasiswaan. }\end{array}$ & $\begin{array}{c}14 \\
(6,4 \%)\end{array}$ & $\begin{array}{c}32 \\
(14,6 \%)\end{array}$ & $\begin{array}{c}51 \\
(23,3 \%)\end{array}$ & $\begin{array}{c}57 \\
(26 \%)\end{array}$ & $\begin{array}{c}47 \\
(21,5 \%)\end{array}$ & $\begin{array}{c}18 \\
(8,2 \%)\end{array}$ & $\begin{array}{c}219 \\
(100 \%)\end{array}$ \\
\hline 2. & $\begin{array}{l}\text { FEB Unib menyediakan slot beasiswa } \\
\text { yang cukup bagi mahasiswa setiap } \\
\text { tahunnya. }\end{array}$ & $\begin{array}{c}10 \\
(4,6 \%)\end{array}$ & $\begin{array}{c}16 \\
(7,3 \%)\end{array}$ & $\begin{array}{c}46 \\
(21 \%)\end{array}$ & $\begin{array}{c}64 \\
(29,2 \%)\end{array}$ & $\begin{array}{c}46 \\
(21 \%)\end{array}$ & $\begin{array}{c}37 \\
(16,9 \%)\end{array}$ & $\begin{array}{c}219 \\
(100 \%)\end{array}$ \\
\hline 3. & $\begin{array}{l}\text { FEB Unib menyediakan pelatihan soft } \\
\text { skill dan hard skill bagi mahasiswa } \\
\text { guna mengasah kemampuan dan } \\
\text { keterampilannya. }\end{array}$ & $\begin{array}{c}9 \\
(4,1 \%)\end{array}$ & $\begin{array}{c}22 \\
(10 \%)\end{array}$ & $\begin{array}{c}42 \\
(19,2 \%)\end{array}$ & $\begin{array}{c}62 \\
(28,3 \%)\end{array}$ & $\begin{array}{c}54 \\
(24,7 \%)\end{array}$ & $\begin{array}{c}30 \\
(13,7 \%)\end{array}$ & $\begin{array}{c}219 \\
(100 \%)\end{array}$ \\
\hline 4. & $\begin{array}{l}\text { FEB Unib memberikan pelatihan } \\
\text { peningkatan soft skill mahasiswa } \\
\text { dalam hal pengelolaan keuangan. }\end{array}$ & $\begin{array}{c}8 \\
(3,7 \%)\end{array}$ & $\begin{array}{c}27 \\
(12,3 \%)\end{array}$ & $\begin{array}{c}45 \\
(20,5 \%)\end{array}$ & $\begin{array}{c}71 \\
(32,4 \%)\end{array}$ & $\begin{array}{c}47 \\
(21,5 \%)\end{array}$ & $\begin{array}{c}21 \\
(9,6 \%)\end{array}$ & $\begin{array}{c}219 \\
(100 \%)\end{array}$ \\
\hline
\end{tabular}




\begin{tabular}{|c|c|c|c|c|c|c|c|c|}
\hline 5. & $\begin{array}{l}\text { FEB Unib berupaya untuk terus } \\
\text { meningkatkan kualitas SDM } \\
\text { karyawannya. }\end{array}$ & $\begin{array}{c}1 \\
(0,5 \%)\end{array}$ & $\begin{array}{c}15 \\
(6,8 \%)\end{array}$ & $\begin{array}{c}41 \\
(18,7 \%)\end{array}$ & $\begin{array}{c}66 \\
(30,1 \%)\end{array}$ & $\begin{array}{c}57 \\
(26 \%)\end{array}$ & $\begin{array}{c}39 \\
(17,8 \%)\end{array}$ & $\begin{array}{c}219 \\
(100 \%)\end{array}$ \\
\hline 6. & $\begin{array}{l}\text { Kami merasa karyawan di FEB Unib } \\
\text { diberikan kesempatan untuk secara } \\
\text { rutin mengikuti pelatihan soft skill dan } \\
\text { hard skill. }\end{array}$ & $\begin{array}{c}1 \\
(0,5 \%)\end{array}$ & $\begin{array}{c}14 \\
(6,4 \%)\end{array}$ & $\begin{array}{c}48 \\
(21,9 \%)\end{array}$ & $\begin{array}{c}66 \\
(27,4 \%)\end{array}$ & $\begin{array}{c}60 \\
(27,4 \%)\end{array}$ & $\begin{array}{c}30 \\
(13,7 \%)\end{array}$ & $\begin{array}{c}219 \\
(100 \%)\end{array}$ \\
\hline 7. & $\begin{array}{l}\text { Kami merasa bahwa karyawan di FEB } \\
\text { Unib diberikan kesempatan yang } \\
\text { memadai untuk meningkatkan } \\
\text { kompetensi melalui degree dan non- } \\
\text { degree training. }\end{array}$ & $\begin{array}{c}0 \\
(0 \%)\end{array}$ & $\begin{array}{c}13 \\
(5,9 \%)\end{array}$ & $\begin{array}{c}48 \\
(21,9 \%)\end{array}$ & $\begin{array}{c}68 \\
(31,1 \%)\end{array}$ & $\begin{array}{c}59 \\
(26,9 \%)\end{array}$ & $\begin{array}{c}31 \\
(14,2 \%)\end{array}$ & $\begin{array}{c}219 \\
(100 \%)\end{array}$ \\
\hline
\end{tabular}

Sumber: Data Primer (2019)

\section{Faktor 5: Kemudahan Peminjaman Ruang}

Faktor 5 hanya dibentuk dari satu indikator yaitu indikator dengan pernyataan kemudahan proses peminjaman ruangan. Distribusi respon responden terhadap indikator ini tersaji pada Tabel 7.

Tabel 7. Kemudahan Peminjaman Ruang

\begin{tabular}{|c|c|c|c|}
\hline No & Jawaban Responden & Frekuensi & Persentase (\%) \\
\hline 1. & Sangat Tidak Setuju & 5 & 2,3 \\
\hline 2. & Tidak Setuju & 12 & 5,5 \\
\hline 3. & Kurang Setuju & 35 & 16 \\
\hline 4. & Cukup Setuju & 74 & 33,8 \\
\hline 5. & Setuju & 62 & 28,3 \\
\hline \multirow[t]{2}{*}{6.} & Sangat Setuju & 31 & 14,2 \\
\hline & Total & 219 & 100 \\
\hline
\end{tabular}

Sumber: Data Primer (2019)

\section{Faktor 6: Perhatian Personal Dosen}

Faktor 6 hanya dibentuk dari satu indikator yaitu indikator dengan pernyataan Dosen responsif terhadap keluhan atau permasalahan yang dialami mahasiswa. Secara umum, hal ini menyiratkan perhatian personal dalam proses penyelenggaraan kegiatan akademik. Distribusi respon terhadap indikator ini tersaji pada Tabel 8.

Tabel 8 Perhatian Personal Dosen

\begin{tabular}{clccc}
\hline No & \multicolumn{1}{c}{ Jawaban Responden } & Frekuensi & Persentase (\%) \\
\hline 1. & Sangat Tidak Setuju & 5 & 2,3 \\
\hline 2. & Tidak Setuju & 15 & 6,8 \\
\hline 3. & Kurang Setuju & 37 & 16,9 \\
\hline 4. & Cukup Setuju & 70 & 32 \\
\hline $\mathbf{5 .}$ & Setuju & 67 & 30,6 \\
\hline $\mathbf{6 .}$ & Sangat Setuju & 25 & 11,4 \\
\hline & & $\mathbf{2 1 9}$ & $\mathbf{1 0 0}$ \\
\hline
\end{tabular}

Sumber: Data Primer (2019) 


\section{PEMBAHASAN}

Berdasarkan hasil analisis data dalam penelitian ini maka, peneliti dapat mengetahui kualitas layanan yang diberikan dosen dan karyawan FEB Unib. Kualitas layanan yang baik adalah yang dapat melebihi ekspektasi pelanggan. Kualitas layanan dalam penelitian ini dibagi ke dalam 6 Faktor. Faktor tersebut terdiri dari Faktor 1 yang berfokus layanan administratif yang diberikan karyawan FEB Unib. Faktor 2 yang berfokus pada sarana dan prasarana yang ada di FEB Unib. Faktor 3 yang berfokus pada kualitas pengajaran. Faktor 4 yang berfokus pada pengalokasian sumber daya. Faktor 5 yang berfokus pada kemudahan peminjaman ruang dan Faktor 6 berfokus pada responsif dosen terhadap keluhan mahasiswa.

Berdasarkan hasil analisis, keenam dimensi tersebut hanya memperoleh dominasi tanggapan cukup setuju. Hanya satu dimensi yang memperoleh tanggapan setuju yaitu kualitas pengajaran yang menyangkut kualitas dosen FEB Unib. Hal ini berarti Dosen FEB Unib sudah berkualitas. Hanya saja beberapa tanggapan responden yang menyatakan tidak setuju bahkan sangat tidak setuju cenderung disebabkan mahasiswa masih merasa beberapa dosen tidak profesionalisme dalam proses perkuliahan terutama dalam pemberian niali. Mahasiswa menginginkan adanya transparansi dalam pemberian nilai selama proses perkuliahan. Selain itu mahasiswa terkhusus semester akhir juga merasakan kesulitan ketika proses bimbingan skripsi karena dosen yang susah untuk ditemui dan kurang memberikan pemahaman yang detail kepada mahasiswa. Sehingga disarankan untuk dosen FEB Unib untuk lebih professional dalam memberikan nilai dan juga lebih peduli terhadap mahasiswa bimbingan masing-masing. Untuk mengatasi keluhan tersebut, kebijakan dari masingmasing Ketua Program Studi untuk menindaklanjuti terutama bagi mahasiswa yang telah menempuh kuliah lebih dari delapan semester.

Dari tanggapan responden mengenai dimensi kualitas layanan walaupun respon mayoritas responden menyatakan cukup setuju, namun jika dilihat secara keseluruhan respon responden bisa disimpulkan bahawa kualitas layanan yang diberikan FEB Unib sudah baik. FEB Unib hanya perlu terus melakukan pembenahan dan mebuat kebijakan terkait dengan keluhan-keluhan mahasiwa. Hal ini dikarenakan menurut Dyson et al (1996) kualitas layanan bagi dunia pendidikan tinggi merupkan aspek penting untuk keungguan bersaing sebuah perguruan tinggi tersebut. Ketika mahasiswa merasakan institusi pendidikan menyediakan lingkungan belajar yang memfasilitasi, infrastruktur yang memadai dan mereka mampu mengembangkan bakat di dalam organisasi, maka mahasiswa akan termotivasi untuk lebih baik belajar di bidang akademik (Alridge dan Rowley, 2001). Selain termotivasi, mahasiswa juga merasakan kepuasan terhadap kualitas layanan (Zeithaml,1988).

\section{KESIMPULAN DAN SARAN}

Berdasarkan analisis data dan pembahasan, maka dapat ditarik kesimpulan bahwa: 1) kualitas layanan yang diberikan karyawan dan dosen dalam memberikan 
layanan kepada mahasiswa Fakultas Ekonomi dan Bisnis sudah cukup baik. FEB UNIB hanya perlu melakukan beberapa perbaikan guna meningkatkan kualitas layanan; 2) Sumber daya Finansial Fakultas Ekonomi dan Bisnis dalam melakukan pembiayaan yang menunjang fasilitas, sarana dan prasarana mahasiswa Fakultas Ekonomi dan Bisnis sudah cukup teralokasikan dengan baik. Hanya saja pihak FEB Unib perlu untuk menjaga sarana dan prasarana yang ada dan transparansi anggaran; 3) Sarana dan Prasarana baik yang dirasakan langsung maupun yang dirasakan tidak langsung oleh mahasiswa di Fakultas Ekonomi dan Bisnis sudah lengkap, hanya perlu untuk pemeliharan bahkan pembaharuan.

Berdasarkan analisis data dan pembahasan, maka saran untuk FEB Unib adalah sebagai berikut: 1) Disarankan kebijakan dari masing-masing Ketua Program Studi untuk memfasilitasi mahasiswa yang telah menempuh kuliah lebih dari delapan semester dalam proses bimbingan skripsi; 2) Disarankan adanya monitoring dan berlakunya piket karyawan di waktu istirahat yang sistematisnya diatur berdasrkan kebijakan FEB Unib; 3) Disarankan kepada pihak FEB Unib untuk memperbaiki, memdayagunakan serta bila memungkinakan untuk menambah sarana prasarana yang ada di selingkung FEB Unib guna proses perkuliahan bejalan kondusif; dan 4) Disarankan untuk pengelola keuangan untuk membuat daftar alokasi dana kegiatan mahasiswa per himpunanan mahsiswa yang ada di selingkung FEB Unib, Kemudian setiap himpunan mahsiswa mengajukan proposal kegiatan pada awal musyawarah kerja dan rapat kerja yang kemudian akan diselesi dan disesuaikan dengan dana yang ada. Sehingga tranparasnsi dana yang dialokasikan lebih jelas, Selain itu proposal kegiatan yang telah mendapatkan persetujuan untuk didanai diumumkan.

\section{DAFTAR PUSTAKA}

Abdullah, F. (2006). The development of HEdPERF: A new measuring instrument of service quality for the higher education sector. International Journal of Consumer Studies, 30(6), 569-581.

Ahmed, I., Nawaz, M. M., Usman, A., Shaukat, Z. M., Ahmad, N. dan Iqbal, H. 2010. "Impact of service quality on customer's satisfaction: Empirical evidence from telecom sector of Pakistan". Interdisciplinary Journal of Contemporary research in Business, 1(12): 98-113

Alridge S. dan Rowley J. 2001. "Conducting a withdrawal survey". Quality in Higher Education, 7(1), 55-63.

Annamdevula, S. dan Bellamkonda, R.S. 2016. "Effect of student perceived service quality on student satisfaction, loyalty, and motivation in Indian universities, 11 (2), 488-517.

Brady, M. K., \& Cronin, J., Jr. (2001). Some new thoughts on conceptualizing perceived service quality: A hierarchical approach. Journal of Marketing, 65(3), 34-49.

Bolton, R.N., Lemon, K.N. and Verhoef, P.C. (2004), "The theoretical underpinnings of customer asset management: a framework and propositions for future 
research", Journal of the Academy of Marketing Science, Vol. 32 No. 3, pp. 271292.

Chua, C. (2004). Perception of Quality in Higher Education, Australian Universities Quality Forum (AUQF) 7-9 July, Adelaide, Australia.

Clewes, D. (2003). A Student-Centered Conceptual Model of Service Quality in. Higher Education. Journal of Quality in Higher Education, 9 (1): p.69-85.

Cooper, D,r dan Schindler, P, S. 2003. "Business Research Method Eight Edition". New York, NY: McGraw-Hill/Irwin.

Cuthbert, P. (1996a). Managing Service Quality in HE: Is SERVQUAL the Answer? Part 1, Managing Service Quality, Vol.6 (2), 11-16.

Cuthbert, P. (1996b). Managing Service Quality in HE: Is SERVQUAL the Answer? Part 2, Managing Service Quality, Vol.6 (3), 31-35.

Deming, W. Edwards. 1982. Guide to Quality Control. Cambirdge: Massachussetts. Institute Of Technology.

Dick A.S dan Basu K. 1994. "Customer Loyalty: Toward an Integrated Conceptual Framework". Journal of the Academy of Marketing Science, 22(2), 99-113.

Dyson P. Farr A. dan Hollis N.S. 1996. "Understanding, Masuring, and Using Brand Equity". Journal of Advertising Research, 36(6), 9-21.

Grönroos, C. (1984), "A Service Quality Model and its Marketing Implications", European Journal of Marketing, Vol. 18 No. 4, pp. 36-44.

Harvey, L., \& Green, D. (1993). Defining Quality. Assessment and Evaluation in Higher Education, 18, 9-34.

Juran, J.M. (1974) Juran's Quality Control Handbook. 3rd Edition. McGraw-Hill, New York.

Kotler, P. 2000. "Marketing Managemnet $10^{\text {th }}$ edn". New Jersey: Prentice-Hall

Lau M,M., Cheung R., Lam A,Y,C dan Chu Y,T. 2013. "Measuring Service Quality in the Banking Industry: A Hongkong Based Study". Coutemporary Managemnet Research Vol. 9 No. 3. September 2013.

Neuman, W. L. (2006). Social research methods qualitative and quantitavie approach (6th ed.). Upper Saddle River Pearson.

O'Neill, M.A. and Palmer, A. 2004. "Importance-performance analysis: a useful tool for directing continuous quality improvement in higher education", Quality Assurance in Education, Vol. 12 No. 1, pp. 39-52.

Parasuraman A., Zeithaml V. A., dan Berry L. L. 1985. "A Conceptual Model of Service Quality and Its Implications for Future Research". Journal of Marketing, 49, 4150.

Parasuraman A., Zeithaml V., dan Berry L. 1988. "SERVQUAL: a Multiple Item Scale for Measuring Consumer Perceptions of Service Quality". Journal of Retailing, 6(1), 12-36.

Parri, J. (2006), "Quality in higher education", Vadyba/Management, Vol. 2 No. 11, pp. 107-111.

Quinn, A., Lemay, G., Larsen, P. and Johnson, D.M. (2009), "Service quality in higher education", Total Quality Management, Vol. 20 No. 2, pp. 139-152

Rahmatina Desi. 2010. "Prosedur Menggunakan Stratified Random Sampling Method dalam Mengestimasi Parameter Populasi”. JEMI Vol.1, No. 1 Desember 2010. 
Sarwono Jonathan. 2006. "Metode Penelitian Kuantitatif dan Kualitatif". Yogyakarta: Graha Ilmu.

Spooren P., Mortelmans D. dan Denekens, J. 2007. "Student Evaluation of Teaching Quality in Higher Education: Development of an Instrument Based on 10 LikertScales". Assessment and Evaluation in Higher Education, 32, 667-679.

Sultan, P. dan Wong, H.Y. 2012. "Antecedents and consequences of service quality in a higher education context a qualitative research approach", Quality Assurance in Education, Vol. 21 No. 1, pp. 70-95

Vazquez. 2001. "Expectations: a comparison standard in measuring service quality: an assessment of a reassessment", Journal of Marketing, Vol. 58 No. 1, pp. 132-9.

Zeithaml V. 1988. "Defining and Relating Price, Perceived Quality and Perceived Value". Cambrige, MA: Marketing Science Institute.

Zeithaml Valerie A dan Bitner Mary Jo. 2000. "Services Marketing". Boston: Irwin MC Graw Hill. 